\title{
CAPACIDADES ESTATAIS E SEUS EFEITOS NAS POLÍTICAS MUNICIPAIS DE EDUCAÇÃO
}

\author{
State Capacities and its Effects on Municipal Education Policies \\ Capacidades estatales y sus efectos en las políticas municipales de Educación
}

\section{RESUMO}

A análise das capacidades estatais é central para a compreensão da implementação de políticas públicas e seus resultados. Ainda que haja um enorme debate em torno do conceito, alguns estudos mostram que duas dimensões da capacidade devem ser consideradas: a técnico-administrativa e a político-relacional. No entanto, há poucos estudos que buscaram compreender em maior profundidade essas dimensões no nível local, já que a literatura esteve mais focada na análise do governo federal. Este artigo busca suprir essa lacuna, analisando a capacidade estatal dos municípios brasileiros a partir do estudo da política de educação e das secretarias municipais de Educação em oito municípios. A análise qualitativa e comparativa de dados coletados entre entrevistas semiestruturadas e observação aponta que ambas as dimensões da capacidade estatal são frágeis em nível municipal. Apesar disso, a autonomia das secretarias e a liderança dos gestores, assim como a relação entre secretarias e escolas, explicam as diferenças na implementação da política educacional entre os municípios analisados.

Palavras-chave: capacidade estatal, burocracia, educação, municípios, políticas públicas.

\section{Catarina lanni Segatto'}

catarina.segatto@gmail.com

ORCID: 0000-0002-5094-8225

\section{Fillipe Maciel Euclydes ${ }^{2}$}

fillipemaciel@gmail.com

ORCID: 0000-0001-8920-1594

\section{Fernando Abrucio ${ }^{2}$}

fabrucio@gmail.com

ORCID: 0000-0002-3883-9915

1 Universidade de São Paulo, Centro de Estudos da Metrópole, São Paulo, SP, Brasil

2 Fundação Getulio Vargas, Escola de Administração de Empresas de São Paulo, São Paulo, SP, Brasil

\section{Artigo convidado}

Editora científica: Alketa Peci

Fundação Getúlio Vargas, Escola Brasileira de Administração Pública e de Empresas, Rio de Janeiro, RJ, Brasil

DOI: http://dx.doi.org/10.12660/cgpc.v26n84.81938

\section{Agradecimentos}

Os autores agradecem aos pesquisadores Caio Momesso, Eliana Lins Morandi, Fernando Burgos Pimentel dos Santos, Kate Dayana R. de Abreu e Marina K. Exner pelas contribuições e ao Centro de Estudos em Administração Pública e Governo (CEAPG/ FGV EAESP) e ao Instituto Votorantim pelo apoio à realização deste estudo.

Esta obra está submetida a uma licença Creative Commons 


\begin{abstract}
The analysis of the state capacities is central to comprehend policy implementation and its outcomes. Even though there is a great debate on the concept of state capacities, some studies show that two dimensions of state capacity should be considered: technical-administrative and political-relational. However, few studies seek to better grasp these two dimensions at local level, as this literature was more focused on the analysis of the federal government. This paper aims to fill this gap by analyzing the state capacity of Brazilian municipalities through a study on education policy and municipal education departments in eight municipalities. A qualitative and comparative analysis of data collected through in-depth interviews and observation points out that both dimensions - technical-bureaucratic and political-relational - are fragile at municipal level. Nevertheless, the departments' autonomy and the leadership of managers, as well as the relationship between departments and schools, explain the differences in the implementation and outcomes of the educational policy in the municipalities analyzed.
\end{abstract}

Keywords: state capacities, bureaucracy, education, municipalities, public policies.

\title{
Resumen
}

El análisis de las capacidades estatales es fundamental para comprender la implementación de las políticas públicas y sus resultados. Aunque existe un gran debate en torno al concepto de capacidad estatal, algunos estudios muestran que dos dimensiones de la capacidad estatal deberían ser consideradas: la técnica-administrativa y la política-relacional. Sin embargo, hay pocos estudios que intentaron comprender

estas dimensiones con mayor profundidad a nivel local, ya que la literatura se centró más en el análisis del gobierno federal. Este artículo busca avanzar en este debate, analizando la capacidad estatal de los municipios brasileños a partir del estudio de la política educativa y las Secretarías de Educación Municipal en ocho municipios. El análisis cualitativo y comparativo de los datos recogidos por medio de entrevistas semiestructuradas y observación muestra que ambas dimensiones, técnica-burocrática y política relacional, de la capacidad estatal son frágiles a nivel municipal. A pesar de esto, la autonomía de los secretarios y el liderazgo de los gestores, as í como la relación entre las Secretarias y las escuelas, explican las diferencias en la implementación y los resultados de la política educativa entre los municipios analizados.

Palabras clave: capacidad estatal, burocracia, Educación, municipios, políticas publicas.

\section{INTRODUÇÃO}

Diversas pesquisas têm procurado compreender como as diferenças nas capacidades estatais influenciam a implementação de políticas públicas e seus resultados (Wu, Howlett, \& Ramesh, 2018). É consenso que a capacidade estatal é relevante para explicar as políticas públicas, no entanto, esse termo "[...] comporta inúmeras definições, cada uma capturando diferentes aspectos do conceito" (Souza \& Fontanelli, 2020, p. 46). Situadas nesse debate, encontram-se discussões que inicialmente estavam ligadas ao conceito de state capacity e, a partir da década de 1990, passaram a incluir a noção de policy capacity. Em seu sentido mais geral, esse conceito refere-se às características e condições que os Estados têm para produzirem - formular, implementar, monitorar e avaliar - políticas efetivas, mas há diferentes possibilidades analíticas sobre como operacionalizar sua conceituação nas análises de políticas públicas (Wu et al., 2018; Souza \& Fontanelli, 2020; Williams, 2020).

No início, os estudos estavam mais relacionados às investigações sobre o papel do Estado enquanto agente promotor de desenvolvimento econômico (Skocpol, 1985; Evans, 1995). Contudo, estudos mais recentes passaram a utilizar o conceito de capacidade estatal na análise das diferentes políticas públicas. Ao realizar essa guinada, as pesquisas 
centraram suas análises em duas dimensões (Pires \& Gomide, 2016). A primeira vinculada mais à questão técnico-administrativa, incluindo a profissionalização da burocracia, considerando autonomia, capacitação e recursos disponíveis, baseando-se na premissa de que, sem um corpo técnico com certa autonomia, a efetividade da ação estatal seria reduzida (Evans, 1995; Fukuyama, 2013). Situados nesse escopo, alguns estudos se debruçaram sobre a relação entre capacidade, implementação e desempenho, mostrando que um corpo técnico mais qualificado influencia positivamente o resultado das políticas públicas (Marenco, 2017). Outros estudos levantam uma segunda dimensão: a capacidade político-relacional, ou seja, a capacidade da burocracia de interlocução e negociação com outros atores (Cingolani, 2013; Souza, 2016; Pereira et al., 2019; Pires \& Gomide, 2016; Koga, Viana, Camões, \& Filgueiras, 2019). A capacidade política pode ser igualmente responsável pela ativação da capacidade técnico-administrativa, influenciando positivamente a implementação e o desempenho governamental (Koga et al., 2019).

De modo geral, o conceito de capacidade estatal é apontado como difícil de ser operacionalizado, na medida em que é um desafio atribuir causalidade entre recursos, processos e resultados, e ser mais adequado para análises agregadas e macro-históricas (Grin, 2016; Gomide, Pereira, \& Machado, 2018; Marenco, 2017; Williams, 2020). Além disso, esse conceito supõe que a burocracia é um ator unitário (Williams, 2020). A partir de um esforço analítico, estudos mais recentes têm buscado desagregar esse conceito a partir das duas dimensões - técnico-administrativa e político-relacional - em indicado- res específicos (Gomide et al., 2018) e em competências - analíticas, operacionais e políticas - em níveis individual, organizacional e sistêmico (Wu et al., 2018).

O presente artigo utiliza o modelo conceitual de capacidade estatal, porque busca contribuir para a compreensão da relação entre a burocracia e a política educacional nos municípios brasileiros a partir de uma análise comparada. No entanto, busca-se ir além de uma análise de um constructo unidimensional ao investigar em maior profundidade as capacidades técnico-administrativa e político-relacional das secretarias municipais de educação e suas implicações nas políticas municipais de educação. A partir de uma seleção estatística, foi feita uma análise qualitativa e comparativa de oito municípios brasileiros, utilizando-se de dados coletados em entrevistas semiestruturadas com gestores, questionários com outros atores relevantes e observação.

Embora a discussão sobre a capacidade técnica e político-relacional da burocracia tenha avançado no Brasil, historicamente a maioria dos estudos esteve focada na análise das políticas de desenvolvimento e infraestrutura adotadas no plano federal. Há um esforço recente de analisar esse tema no nível subnacional, especialmente, no plano municipal (Arretche, Cordeiro, Fusaro, Dias, \& Bittar, 2012; Bichir, Junior, \& Pereira, 2020; Grin \& Abrucio, 2019; Lavalle, Rodrigues, \& Guicheney, 2019), mas ainda são poucos os estudos sobre o tema. $O$ interesse analítico aqui é avançar na discussão sobre o uso desse conceito para compreender a formulação e a implementação de políticas públicas e seus efeitos. 
A insuficiência da literatura é ainda maior quando o objeto empírico é a educação, em particular a análise do processo de implementação em nível local. Ainda se sabe pouco sobre como os atores burocráticos afetam as políticas educacionais no Brasil. Além disso, a descentralização impulsionada pela Constituição de 1988 deu um lugar central às redes municipais. Hoje, os municípios são responsáveis pela oferta da educação infantil e do ensino fundamental e pouco se sabe sobre o seu papel político-administrativo nesse processo, sendo essa mais uma justificativa deste trabalho.

\section{DIMENSÕES TÉCNICA E POLÍTICA: RE- TOMANDO UM DEBATE}

Desde Woodrow Wilson e Max Weber, a preocupação com o funcionamento das organizações públicas é objeto central nas investigações sobre a atuação do Estado. A visão wilsoniana apontava que a administração pública deveria ser orientada pelo mérito e pela especialização a partir de um corpo técnico e especializado de burocratas, que executaria as decisões tomadas por políticos (Wilson, 2005). Na noção weberiana, as organizações complexas seguiriam para uma racionalização progressiva (Weber, 1993), com objetivos claramente definidos, que são mais bem atingidos por uma estrutura formal orientada por regras, procedimentos e decisões baseadas em conhecimento especializado.

Estudos mais recentes mostraram que a burocracia como estrutura monolítica era incompatível com um Estado que complexificou suas funções, especialmente após a Segunda Guerra Mundial. Nesse contexto, alguns autores defenderam que os burocra- tas podem ser neutros e impessoais, obedecendo ao que os políticos determinam, mas podem ser atores políticos, defendendo interesses específicos (Aberbach, Putnam, \& Rockman,1981; Edigheji, 2010; Evans, 2010, 2011). Assim, constituiu-se um consenso, na literatura, de que os papéis de agentes políticos e burocratas são mais sobrepostos e variados; o burocrata precisa ter, em determinados momentos, uma capacidade política que se torna, ao lado da técnica, uma habilidade fundamental para responder às demandas dos cidadãos e promover maior articulação entre os diversos atores.

Ainda assim, a capacidade técnico-administrativa permanece como um elemento central nos processos de implementação das políticas públicas. Segundo Fukuyama (2013), algumas características das organizações públicas, como uma burocracia técnica, explicaria a maior ou menor capacidade do governo na tomada de decisões e na prestação de serviços. Outro elemento importante seria a autonomia, que serviria para afastar a burocracia das relações patrimoniais e discricionárias e para reduzir as disfuncionalidades de um "microgerenciamento" das atividades administrativas (Fukuyama, 2013). No entanto, uma autonomia completa levaria a burocracia a definir sua própria agenda, independentemente da arena político-partidária, trazendo graves problemas relacionados à accountability (Loureiro, Olivieri, \& Martes, 2010).

De modo paralelo, várias pesquisas apontam que empiricamente inexiste uma completa separação entre o Estado e a sociedade (Selznick, 1984; Evans, 1995; Edigheji, 2010). Sempre há algum grau de imbricamento entre a burocracia e seu entorno, de modo que 
os burocratas não são impermeáveis, como imaginavam os pais fundadores das teorias da burocracia. Nesse sentido, estudos apontaram que, além do saber técnico, os burocratas necessitavam cooptar ou buscar apoio de outros atores para alcançar os objetivos organizacionais (Selznick, 1984). A importância da dimensão político-relacional esteve presente em diversos trabalhos, como em Cardoso (1975), Carpenter (2001), Evans $(2010,2011)$ e Harris (2017), mas foi pouco desenvolvida.

Em função das dificuldades de operacionalização dessas dimensões para a análise empírica, estudos mais recentes buscaram desagregá-las em indicadores específicos. De um lado, a capacidade técnico-administrativa envolve recursos humanos, financeiros e tecnológicos adequados e disponíveis, instrumentos de coordenação intra e intergovernamentais e estratégias de monitoramento e avaliação das ações (Peters, 2015; Souza, 2016). De outro, a capacidade político-relacional inclui mecanismos de interação das burocracias do Executivo com atores do sistema político-representativo, canais institucionalizados nos processos decisórios e articulação com os órgãos de controle interno e externo (Gomide et al., 2018).

Outra abordagem que propõe uma operacionalização desse conceito empiricamente é a de Wu et al. (2018). Nesse caso, os autores usam o conceito de policy capacity como o conjunto de competências e recursos necessários para desempenhar funções políticas, que podem ser de três tipos: analítica, vinculada ao alcance dos objetivos da política; operacional, que permite que os recursos sejam alinhados às ações para a implementação das políticas na prática; e política, que envolve a negociação e a construção de consenso com stakeholders e a comunicação com eles. No nível individual, são analisados os papéis dos burocratas, ou seja, como desempenham atividades e funções; conhecimentos e competências sobre as políticas, desenhando e comparando problemas e soluções, formulando planos, avaliando e analisando políticas; conhecimento gerencial e julgamento político. No nível organizacional, são analisados a existência de uma estrutura de informações e processos e mecanismos de gerenciamento de pessoas e recursos financeiros. No nível sistêmico, são analisados o acesso a stakeholders, os sistemas de aconselhamento e comunidades de políticas, as formas de coordenação e de accountability (Wu et al., 2018).

Há poucos estudos sobre a capacidade estatal em nível local. No Brasil, os estudos sobre municípios brasileiros mostram que houve avanços, mas há ainda fragilidades e uma enorme diversidade entre os municípios. Essa diversidade pode estar relacionada às induções federais e ao legado das políticas, à centralidade de cada setor na agenda pública, ao perfil dos gestores municipais e ao perfil socioeconômico dos municípios (Bichir et al., 2020; Lavalle et al., 2019). Nesses estudos, as capacidades variam a partir da análise dos seguintes fatores: existência de órgãos destinados à gestão da política; características de seus recursos humanos; infraestrutura de equipamentos de prestação de serviços; cadastros próprios e/ou fontes de informação sobre público-alvo; e serviços e existência de consórcios intermunicipais, de instâncias de participação social e de fundos específicos (Arretche et al., 2012; Bichir et al., 2020; Grin \& Abrucio, 2019; Lavalle et al. 2019). 


\section{METODOLOGIA}

A partir desse debate, buscou-se operacionalizar o conceito de capacidade estatal para a compreensão desse fenômeno nos municípios brasileiros e suas implicações nas políticas de educação. Como sintetizado no Quadro 1, este estudo se baseou na análise das capacidades técnico-admi- nistrativa e político-relacional das secretarias municipais de Educação; não incluímos, nesse estudo, a análise de outros tipos de capacidades, como fiscal e de provisão. A autonomia, entendida como a existência de um órgão gestor e o espaço decisório existente, também foi incluída na análise como um fator necessário para o exercício dessas capacidades.

Quadro 1. Modelo de análise das capacidades no nível local

\begin{tabular}{|c|c|c|}
\hline Capacidade & Organizacional & dividual \\
\hline $\begin{array}{l}\text { Técnico-admi- } \\
\text { nistrativa }\end{array}$ & $\begin{array}{l}\text { Recursos humanos, financeiros e tecnoló- } \\
\text { gicos adequados e disponíveis, principal- } \\
\text { mente nas áreas estratégicas - pedagógi- } \\
\text { ca e administrativo-financeira. } \\
\text { Sistemas de informação e estratégias de } \\
\text { monitoramento e avaliação das ações. } \\
\text { Instrumentos de coordenação intra e inter- } \\
\text { governamentais. } \\
\text { Existência de processos e mecanismos } \\
\text { institucionalizados e previamente definidos } \\
\text { de gerenciamento de pessoas e recursos } \\
\text { financeiros. }\end{array}$ & $\begin{array}{l}\text { Perfil e trajetória do secretário } \\
\text { e dos gestores. } \\
\text { Papéis dos gestores e buro- } \\
\text { cratas no processo de deci- } \\
\text { são e implementação. } \\
\text { Práticas, conhecimentos e } \\
\text { competências nas políticas e } \\
\text { em seus instrumentos. }\end{array}$ \\
\hline $\begin{array}{l}\text { Político-rela- } \\
\text { cional }\end{array}$ & $\begin{array}{l}\text { Parcerias formalizadas com outras organi- } \\
\text { zações públicas, organizações privadas e } \\
\text { da sociedade civil. } \\
\text { Mecanismos institucionalizados de rela- } \\
\text { cionamento com Legislativo, Judiciário e } \\
\text { órgãos de controle. } \\
\text { Papel dos conselhos de participação so- } \\
\text { cial. } \\
\text { Mecanismos de comunicação entre secre- } \\
\text { tarias de educação e escolas. } \\
\text { Participação em consórcios e arranjos. }\end{array}$ & $\begin{array}{l}\text { Relações entre gestores das } \\
\text { secretarias de educação e } \\
\text { gestores de outros órgãos e } \\
\text { organizações. } \\
\text { Relação entre coordenadores } \\
\text { pedagógicos e equipes de } \\
\text { gestão escolar. } \\
\text { Participação de gestores em } \\
\text { redes e comunidades de po- } \\
\text { líticas. }\end{array}$ \\
\hline
\end{tabular}


Para compreender as capacidades técnico-administrativa e político-relacional dos burocratas das secretarias municipais de Educação e suas implicações nas políticas educacionais, foram analisados comparativamente oito municípios. No processo de seleção, foram escolhidos pares de municípios semelhantes e comparáveis em seus contextos e resultados educacionais no t0 a partir de uma clusterização $k$-means (não hierárquica), para que se pudesse observar se houve mudanças nos seus resultados no momento seguinte. A clusterização permitiu agrupar municípios segundo as variáveis de interesse minimizando o somatório da variância interna (entre os municípios que fazem parte) de cada cluster. As variáveis para clusterização incluíram: população municipal total; percentual da população urbana; população de 6 a 10 anos de idade (pro- xy para o tamanho da rede escolar EF1, que é atribuição dos municípios); IDHM Renda; IDHM Longevidade; IDHM Educação; Índice de Gini (dados coletados no PNUD - Atlas do desenvolvimento, considerando a média de 2000 e 2010, já que o programa foi iniciado em 2008); IDEB Redes Municipais - Anos Iniciais (2007) e IDEB Redes Municipais - Anos Iniciais (2009) (dados coletados no INEP).

Além disso, utilizamos os seguintes critérios para minimizar as diferenças nos contextos: ser do mesmo Estado e) menor diferença nos indicadores selecionados para a clusterização entre os municípios. Assim, foram selecionados quatro pares de municípios (oito municípios), sendo que em cada um foram selecionados pares de escolas (dezesseis escolas).

Tabela 1. Variáveis socioeconômicas e educacionais dos municípios

\begin{tabular}{|c|c|c|c|c|c|c|c|c|c|c|c|}
\hline \multicolumn{2}{|c|}{ Municípios } & \multirow{2}{*}{$\begin{array}{l}\text { IDH } \\
\text { Renda* } \\
0,681\end{array}$} & \multirow{2}{*}{$\begin{array}{l}\text { IDH } \\
\text { Longevi- } \\
\text { dade* }^{*} \\
0,782\end{array}$} & $\begin{array}{l}\text { IDH } \\
\text { Escolari- } \\
\text { dade* }^{*}\end{array}$ & $\begin{array}{l}\text { Índice de } \\
\text { Gini }^{*}\end{array}$ & $\begin{array}{l}\text { Pop. } \\
\text { total }^{\star}\end{array}$ & $\begin{array}{l}\text { Percentual } \\
\text { pop. urba- } \\
\text { na* }\end{array}$ & $\begin{array}{l}\text { Pop. 6-10 } \\
\text { anos* }^{*}\end{array}$ & $\begin{array}{l}\text { Ideb } \\
2007^{* *}\end{array}$ & $\begin{array}{l}\text { Ideb } \\
2009^{* *}\end{array}$ & $\begin{array}{l}\text { Ideb } \\
2017^{* \star}\end{array}$ \\
\hline \multirow{2}{*}{ Par 1} & 1 & & & 0,561 & 0,565 & 17.125 & $56,69 \%$ & 1.654 & 4,8 & 4,9 & 6,7 \\
\hline & $2^{* * *}$ & 0,653 & 0,797 & 0,554 & 0,555 & 19.881 & $61,85 \%$ & 1.958 & 4,7 & 5 & 6,4 \\
\hline \multirow{2}{*}{ Par 2} & 3 & 0,669 & 0,820 & 0,548 & 0,505 & 21.306 & $76,79 \%$ & 1.602 & 4,7 & 5,7 & 6,6 \\
\hline & $4^{\star \star \star}$ & 0,688 & 0,814 & 0,566 & 0,505 & $19.325,5$ & $79,79 \%$ & 1.661 & 4,8 & 5,7 & 6,7 \\
\hline \multirow{2}{*}{ Par 3} & $5^{\star * *}$ & 0,696 & 0,787 & 0,488 & 0,430 & 9.060 & $43,50 \%$ & 788,5 & 5,1 & 5,2 & 6,5 \\
\hline & 6 & 0,638 & 0,790 & 0,504 & 0,450 & $6.756,5$ & $37,39 \%$ & 662 & 4,9 & 5,2 & 7,4 \\
\hline & $7^{* \star *}$ & 0,677 & 0,818 & 0,895 & 0,505 & $67.800,5$ & $34,09 \%$ & $6.338,5$ & 4,2 & 4,9 & 5,6 \\
\hline $\begin{array}{l}\text { Con- } \\
\text { troles }\end{array}$ & $8^{\star \star *}$ & 0,734 & 0,818 & 0,673 & 0,500 & 201.253 & $97,24 \%$ & 16.137 & 5,1 & 5,6 & $\begin{array}{l}6,4 \\
(2015)\end{array}$ \\
\hline
\end{tabular}

*Média de 2000 e 2010

**Anos inicias na rede municipal

*** Municípios que recebem apoio 
Selecionamos municípios similares em suas características socioeconômicas, sendo dois deles relativamente maiores para funcionarem como controles, e Ideb similares em 2007. Metade desses municípios tiveram uma assistência técnica em gestão educacional, o que se esperava que tivesse influenciado seus Ideb positivamente. Todavia, isso não ocorreu. A partir disso, buscou-se compreender como a capacidade estatal influencia as políticas municipais de educação e pode explicar os maiores avanços nos Ideb em alguns municípios.

A pesquisa de campo incluiu observação e entrevistas semiestruturadas com secretários municipais de Educação e gestores responsáveis pelas áreas administrativo-financeira e pedagógica, incluindo supervisores pedagógicos. Além disso, entrevistamos diretores de escolas, vice-diretores (quando havia), coordenadores pedagógicos e professores. Foram realizadas cerca de 70 entrevistas, considerando os oito municípios analisados, e as visitas em campo ocorreram em 2019 e 2020.

Para operacionalização da análise, primeiramente, empregamos a estratégia within-cases, que visa a interpretar o conjunto de dados considerando seus respectivos contextos e os temas preponderantes que emergem (Ayers, Kavanaugh, \& Knafl, 2003). Em seguida, realizou-se uma análise across-cases para comparar dimensões e temas significativos entre os casos (Ayers et al., 2003). Ressaltamos que as variações e comparações entre os casos foram constantemente revisadas no intuito de obter padrões analíticos e explicações capazes de conectar os diferentes municípios investigados.
Baseados em uma perspectiva qualitativa, os dados coletados foram analisados e estão descritos na próxima seção a partir do seguinte recorte: capacidade técnico-administrativa e político-relacional das secretarias/departamentos municipais de Educação, como descrito no Quadro 1; políticas municipais de educação, isto é, currículo, formações, avaliações e outros programas próprios e programas federais e estaduais; e relação entre capacidades e políticas. Este último aspecto, em outras palavras, leva à seguinte pergunta: maior capacidade estatal conduz a melhores políticas? Se sim, quais fatores podem indicar essa relação?

\section{A CAPACIDADE DOS MUNICÍPIOS BRASI- LEIROS NA EDUCAÇÃO}

Antes de discutir os resultados deste estudo, é necessário apresentar uma contextualização da política educacional brasileira, cuja construção deu-se de maneira descentralizada, contando, principalmente, com ofertas estaduais de matrículas e, em menor medida, de provisão municipal. Esse modelo dual, descentralizado e sem coordenação não foi totalmente alterado pela Constituição Federal de 1988. Ainda que ela tenha dividido as competências entre Estados e municípios, manteve ambos os responsáveis pela provisão do ensino fundamental. Apesar disso, determinou que deveria haver um regime de colaboração entre governos subnacionais e uma atuação mais coordenadora do governo federal a partir de assistência técnica e financeira (Brasil, 1988).

A ampliação da coordenação do governo federal ocorreu a partir da segunda metade da década de 1990, por meio da transferência 
de recursos via implementação de programas federais e aprovação de padrões mínimos nacionais. Nos municípios analisados, a relação com o governo federal tornou-se determinante para as políticas municipais, por meio programas como o Programa Nacional de Alimentação Escolar (PNAE), o Programa Nacional de Transporte Escolar (PNTE), o Programa Nacional do Livro Didático (PNDL) e o Programa Dinheiro Direto na Escola (PDDE). Além desses, a maioria deles implementa o Mais Educação e o Programa Nacional de Alfabetização na Idade Certa (PNAIC).

Em relação ao papel dos Estados, há uma enorme variação nas relações entre governos estaduais e municípios no Brasil (Segatto \& Abrucio, 2018), algo que foi observado também nos municípios analisados. Em apenas dois casos, os professores têm acesso às formações online sobre o currículo estadual e, em cerca de metade deles, os municípios aderiram a programas estaduais, que envolvem planejamento, distribuição de materiais pedagógicos e formações mensais para os assessores pedagógicos das secretarias municipais. Na medida em que a colaboração com os governos estaduais não é bem coordenada, o governo federal torna-se a maior referência de gestão para a grande maioria das municipalidades.

Nas últimas duas décadas, as diretrizes nacionais, além de terem provocado os municípios a implementarem determinados programas, induziram-nos a adotarem planos municipais e conselhos de participação social (Grin, 2016). No entanto, constatou-se na amostra selecionada uma baixa influência da participação social na gestão educacional das secretarias analisadas e nas po- líticas municipais. Em alguns casos, foram relatadas reiteradas críticas relacionadas ao esvaziamento dos conselhos municipais de educação ou, em outros casos, os conseIhos não foram citados como instituições relevantes para a política educacional.

A capacidade das secretarias e dos departamentos de Educação

As secretarias e os departamentos de Educação analisados variam em suas estruturas e desenhos organizacionais, mas é comum que estas sejam compostas por duas áreas principais: uma responsável pela política educacional e coordenação pedagógica e outra pela gestão administrativa e financeira. As áreas pedagógicas são normalmente divididas entre os servidores que exercem as funções de planejamento e outros de coordenação, supervisão e apoio às escolas. Eles podem estar divididos por etapas de ensino e função, ou seja, formação e supervisão, por exemplo. No caso da formação, ela pode ser dividida segundo as áreas do conhecimento, havendo, por exemplo, um responsável por Matemática e um por Português. Nessas áreas, não há uma carreira específica, mas os gestores responsáveis são diretores e coordenadores pedagógicos considerados bem-sucedidos em suas experiências profissionais anteriores.

Os servidores responsáveis pela formação e supervisão são peças-chave nas secretarias, pois conectam o comando da rede às escolas, a partir do contato direto com os diretores, coordenadores pedagógicos e professores. Os coordenadores técnico-pedagógicos que fazem a supervisão pedagógica das escolas, acompanham a implementação do currículo e de outros programas, 
bem como a aprendizagem dos alunos a partir da relação com os diretores e visitas às escolas. Na maioria dos municípios, as visitas incluem orientações, mas não observação da sala de aula, sendo, desse modo, uma orientação para a gestão escolar. Outros momentos em que eles entram em contato com as escolas acontecem nas ocasiões de planejamento, acompanhamento, replanejamento (meio do ano), avaliação do final de ano, formações, visitas à escola e convocação de diretores.

Esses supervisores, ao servirem de ponte entre organizações - escolas e secretaria -, assumem a função de "intermediadores" (brokers), podendo facilitar o fluxo de informações e ideias, além de fomentar confiança e capital social entre os vários atores (capacidade político-relacional). Sob risco de fragilizar a cadeia da política municipal de educação, esses burocratas precisam combinar elementos da racionalidade técnica e política para exercer essa articulação.

É interessante notar aqui que boa parte da capacidade estatal na área mais central da atividade educacional vem de profissionais recrutados das escolas, e não de uma carreira específica das secretarias. Isso é um problema do ponto de vista da formação de capacidade técnica própria. Por outro lado, sua condição de atores escolares facilita a articulação com o atividade-fim da educação, aumentando a capacidade político-relacional da secretaria. De todo modo, um cenário intermediário, que garantisse maior continuidade de pessoas e memória administrativa na rede e mantivesse um bom contato com as escolas, seria o mais desejável. Cabe frisar, todavia, que a maioria das secretarias não possuem, conforme relato dos entrevistados, número suficiente de servidores na área de supervisão escolar para realizarem o acompanhamento das escolas de maneira efetiva. Apenas duas secretarias apresentam relação adequada entre número de servidores e escolas, permitindo que eles façam visitas frequentes às escolas. Naquelas que conseguem fazer um acompanhamento mais próximo, o tipo de acompanhamento pode variar, ou seja, não há um padrão mínimo na atuação desses profissionais, havendo grande discricionariedade em como esse acompanhamento é feito. Em um caso, ela estava mais relacionada a um apoio cotidiano às escolas, buscando assessorá-las na construção de seus projetos. Em outro, a coordenação pedagógica envolvia um controle maior das escolas.

As áreas administrativo-financeiras são responsáveis por contratos, compras, transporte, gestão do patrimônio e outros processos. A experiência profissional prévia dos gestores varia, sendo, em alguns casos, diretores e coordenadores pedagógicos e, em outros, servidores que trabalharam com essas questões em outras secretarias. Em função disso, alguns deles relatam desafios relacionados à gestão administrativa e financeira, especialmente adesão e prestação de contas de programas federais.

Mais importante do que isso, observa-se que a maioria dos municípios possui secretarias de educação. Somente no município 1, o Departamento de Educação não tem status de secretaria, o que pode justificar a baixa autonomia financeira e decisória observada nesse caso. Segundo relatado pela Coordenadora Técnico-Pedagógica, "por ser um Departamento, aqui a gente só lida com a parte pedagógica, a parte financeira quem 
lida é a Prefeitura". No entanto, os servidores do Departamento Municipal de Educação acreditam que o departamento responsável pelas decisões financeiras da Prefeitura não aprova todos os gastos em educação solicitados; sobre isso, a diretora do Departamento de Educação afirmou "sempre tem uma barreira lá".

Não obstante, na maioria dos municípios, entrevistados relataram diversos exemplos nos quais foram registradas restrições na gestão financeira em que as decisões finais sobre os gastos foram historicamente tomadas por departamentos responsáveis pela gestão financeira da Prefeitura ou mesmo pelo gabinete do prefeito. Nesses municípios, os entrevistados afirmaram que são dependentes de técnicos e gestores da Secretaria de Finanças ou da Fazenda para realizar empenhos e pagamentos, afirmando que "não há autonomia administrativa e financeira" (secretário Municipal 3). Por outro lado, duas secretarias (2 e 8) foram capazes de aumentar sua autonomia na tomada de decisões financeiras nos últimos anos.

Nessa área (administrativo-financeira), a divisão das funções não obedece a um padrão, ou seja, algumas secretarias dividem contratos e prestação de contas, por exemplo, ao passo que outras dividem transporte, compras e contratos. Ainda, segundo relatado nas entrevistas, há uma falta de coordenação entre os setores, erros e "idas e vindas" nas documentações. Na visão do gestor financeiro do município 8, "este é um dos grandes desafios, já que a coordenação entre essas áreas seria central para a implementação de políticas e programas mais coerentes".
Pode-se afirmar, de modo geral, que há fragilidade nos processos que envolvem os departamentos ou coordenações responsáveis pelas áreas pedagógica e administrativo-financeira, sendo pouco claros para os servidores e pouco institucionalizados. Nos municípios 4, 5 e 8, por exemplo, diferentes responsáveis pela coordenação administrativo-financeira apontaram que aprenderam o que sabem sobre contratos, prestação de contas e legislação sozinhos, de maneira informal. Essa questão é registrada numa outra perspectiva pelo secretário de Educação do município 2, segundo o qual "não havia uma "memória" na secretaria do que havia sido implementado nas últimas gestões (...)", e as reuniões de transição de equipe de gestão "foi para mostrar as diferentes pastas e documentos da secretaria, onde estava cada coisa, mas não tratar do sistema municipal de educação (...) e esse aprendizado se deu na prática".

Nota-se que o processo de aprendizagem é relatado pelos entrevistados como sendo em sua maioria informal, por meio de experiências acumuladas individualmente pelos próprios atores. Essa ausência/ineficiência de processos institucionalizados que busquem alinhar e capacitar esses burocratas amplifica a subjetividade de um processo que é, naturalmente, sensível às condições contextuais, tornando a implementação das políticas municipais de educação ainda mais dependentes das trajetórias e experiências individuais. Em outras palavras, a informalidade e a baixa institucionalização das práticas administrativas tiveram um importante papel de redução das capacidades estatais dos municípios analisados. Essa ausência de institutos ou processos que estoquem o conhecimento amplifica, por exemplo, a 
possiblidade de erros ou do mau uso dos recursos, algo registrado nas entrevistas. Dois exemplos disso: no município 5, a coordenadora administrativo-financeira apontou que houve pagamento de funcionários que não estavam alocados na Educação com recursos dessa secretaria e, no município 4 , registrou-se o receio de que alguns gastos declarados como realizados na Educação sejam considerados de outras pastas.

O balanço da gestão administrativa e financeira do conjunto dessas secretarias municipais de educação revela o quanto essa área é frágil não só em termos de estrutura técnica permanente, mas sobretudo em relação às suas capacidades relacionais frente ao restante do governo. Essa fragilidade é um obstáculo para que a política educacional seja de fato estratégica e menos suscetível a flutuações políticas conjunturais.

\section{As políticas municipais de educação}

A maior parte dos municípios pesquisados ainda não possui um currículo próprio. Apesar disso, os governos locais têm orientado suas políticas segundo a diretriz nacional e os currículos estaduais. No município 3, a secretaria municipal tem pressionado os professores a estudarem o currículo estadual coletivamente no Horário de Trabalho Pedagógico Coletivo (HTPC), e individualmente por meio de leituras e cursos à distância. Entretanto, isso tem sido exigido sem a devida orientação pedagógica (capacidade político-relacional), gerando conflitos entre a secretaria e os professores. Diferentemente, no município 4 , esse processo incluiu uma discussão dos aspectos principais do currículo nas reuniões de HTPC e das formações que orientavam a adequação a partir dos livros didáticos adotados. Além disso, nesse município, em 2017 e 2018, houve formação dada pela Editora Moderna sobre a BNCC e o livro didático da mesma editora adotado pelo município. A maior capacidade técnico-administrativa e político-relacional da secretaria manifestou-se claramente aqui como um diferencial de políticas.

Além dos currículos, as políticas municipais de educação, de modo geral, compreendem: formação dos professores, instrumentos de avaliação e outros programas, incluindo de recuperação, contínua ou paralela, para os alunos com maiores dificuldades de aprendizagem. Em relação à formação de professores, é adotada em momentos específicos durante o ano e a formação em serviço, que ocorre comumente no HTPC. Isso significa que a secretaria oferece formação para diretores, vice-diretores e coordenadores pedagógicos, que devem formar os professores em cada escola, ou determinam os temas que devem ser discutidos nesse horário. Em um dos casos, a secretaria reúne-se semanalmente com a direção da escola para discutir as necessidades e, a partir daí, construir a formação que será oferecida para vice-diretores e coordenadores. Destaca-se que formações sobre práticas e métodos de ensino somente foi verificada em dois municípios.

Em três municípios, há uma articulação maior entre avaliação e formação. Em um dos casos, a secretaria alinha formação à avaliação, uma vez que busca discutir os temas que serão tratados na formação com base nas sondagens com os alunos e nas provas, e, a partir dos resultados, busca identificar os conteúdos que precisam melhorar e, portanto, devem estar no processo de formação. Isso é possível porque o município 
possui uma avaliação própria, que permite monitorar o processo de aprendizagem, verificando se o professor está trabalhando determinados conteúdos da forma correta. Os resultados da avaliação também permitem que seja elaborado um plano de ação individual de cada aluno, de modo a orientar a atuação dos professores em relação àqueles que estão com maior dificuldade de aprendizado.

Ainda que haja uma variação na existência de sistemas de avaliação municipais, todas as redes orientam as suas políticas e assessorias às escolas segundo as avaliações nacionais e as notas do ldeb. Conforme um dos diretores entrevistados, "todas as ações da escola são intermediadas por esse resultado. Agora, estamos focando no Ideb de 2021", o que é corroborado pelo secretário de Educação "a gente fica bem em cima. Fazemos visitas bem pontuais para que não fuja da nossa meta". Em outro município, por exemplo, a secretária incentiva o uso de avaliações, faz visitas às escolas para falar sobre a importância do Ideb e a responsabilidade de todos para a sua meIhoria, inclusive dos alunos, e exige que os diretores elaborem gráficos e meçam as melhorias nos resultados dos alunos.

Nesses casos, as avaliações têm sido usadas para a formulação da política, funcionando como um mecanismo de retroalimentação e aprendizagem. Um dos secretários comentou que "depois dos resultados da ANA [Avaliação Nacional da Alfabetização], optamos por fazer um projeto de leitura, para que as crianças tenham uma aula por semana apenas para ler, sem cobrança, para que não associem a leitura a algo chato".

Finalmente, as dificuldades de aprendizagem são, no geral, combatidas com programas de recuperação, contínua ou paralela, pela maioria das secretarias. Em um dos municípios, por exemplo, há o projeto de Professores Recuperadores, que dão aulas de reforço no contraturno para alunos de todos os anos que tenham dificuldades de aprendizagem, sendo o material preparado pelos próprios professores.

\section{As capacidades e seus efeitos}

É interessante notar que os municípios estudados não têm um Ideb ruim, embora a maioria não seja líder nesse indicador (as exceções incluem o município 6, com o maior Ideb, e o município 7, com o pior ldeb). No entanto, os municípios variam no que se refere às capacidades de suas secretarias e políticas de educação, assim como em seus Idebs. Alguns cresceram mais ao longo do tempo do que outros (entre to e t1), e, para compreender se esse crescimento foi influenciado pelas capacidades e políticas, é necessário comparar os municípios e verificar se há relação entre capacidades, políticas e resultados. 
Catarina Ianni Segatto - Fillipe Maciel Euclydes - Fernando Abrucio

\section{Quadro 2. Comparação entre autonomia, capacidade e políticas nos municípios analisados}

\begin{tabular}{|c|c|c|c|c|}
\hline $\begin{array}{l}\text { Muni- } \\
\text { cípio }\end{array}$ & $\begin{array}{l}\text { Variação } \\
\text { do Ideb }\end{array}$ & Autonomia & Capacidades & Políticas \\
\hline 1 & $36 \%$ & $\begin{array}{l}\text { Dependência de outras pas- } \\
\text { tas sobre o orçamento e a } \\
\text { aplicação dos recursos }\end{array}$ & $\begin{array}{l}\text { Média capacidade político-relacional interna } \\
\text { e externa, mas baixa técnico-administrativa } \\
\text { (mas equipe conhece a política) }\end{array}$ & $\begin{array}{l}\text { Objetivos estratégicos claros e } \\
\text { foco em avaliações e resultados } \\
\text { educacionais }\end{array}$ \\
\hline 2 & $28 \%$ & $\begin{array}{l}\text { Dependência de outras } \\
\text { pastas sobre o orçamento, } \\
\text { mas autonomia na execução } \\
\text { financeira dos recursos }\end{array}$ & $\begin{array}{l}\text { Média capacidade político-relacional interna } \\
\text { e externa (com outros municípios), mas baixa } \\
\text { técnico-administrativa (mas equipe conhece } \\
\text { a política) }\end{array}$ & $\begin{array}{l}\text { Alta descontinuidade e objetivos } \\
\text { estratégicos não claros, mas ten- } \\
\text { tativa de construir uma política de } \\
\text { longo prazo que garanta o direito } \\
\text { à educação }\end{array}$ \\
\hline 3 & $15 \%$ & $\begin{array}{l}\text { Dependência de outras pas- } \\
\text { tas sobre o orçamento e a } \\
\text { aplicação dos recursos }\end{array}$ & $\begin{array}{l}\text { Média capacidade político-relacional interna } \\
\text { (é próxima, ainda que conflituosa), mas baixa } \\
\text { capacidade técnico-administrativa e político- } \\
\text {-relacional externa }\end{array}$ & $\begin{array}{l}\text { Objetivos estratégicos claros e } \\
\text { formação relacionada ao BNCC } \\
\text { (programa estadual) (imposto pela } \\
\text { secretaria) }\end{array}$ \\
\hline 4 & $17 \%$ & $\begin{array}{l}\text { Dependência de outras } \\
\text { pastas sobre o orçamento, } \\
\text { mas autonomia na execução } \\
\text { financeira dos recursos }\end{array}$ & $\begin{array}{l}\text { Média capacidades técnico-administrativa } \\
\text { (equipe conhece a política) e político-relacio- } \\
\text { nal interna e externa (outros municípios) }\end{array}$ & $\begin{array}{l}\text { Objetivos estratégicos claros e } \\
\text { planejamento coordenado das } \\
\text { atividades escolares, mas foco ex- } \\
\text { cessivo em reforço (contraturno) }\end{array}$ \\
\hline 5 & $25 \%$ & $\begin{array}{l}\text { Dependência de outras } \\
\text { pastas sobre o orçamento, } \\
\text { mas autonomia na execução } \\
\text { financeira dos recursos }\end{array}$ & $\begin{array}{l}\text { Baixa capacidade interna (conflituosa), mas } \\
\text { média capacidades técnico-administrativa e } \\
\text { político-relacional externa (outros municípios) }\end{array}$ & $\begin{array}{l}\text { Alta descontinuidade, objetivos } \\
\text { estratégicos não claros e foco em } \\
\text { avaliações e resultados educacio- } \\
\text { nais (imposto pela secretaria) }\end{array}$ \\
\hline 7 & $14 \%$ & $\begin{array}{l}\text { Dependência de outras } \\
\text { pastas sobre o orçamento, } \\
\text { mas autonomia na execução } \\
\text { financeira dos recursos } \\
\end{array}$ & $\begin{array}{l}\text { Baixa capacidades técnico-administrativa e } \\
\text { político-relacional interna e externa (ainda } \\
\text { que a equipe conheça a política) }\end{array}$ & $\begin{array}{l}\text { Objetivos estratégicos não claros, } \\
\text { mas implementação de mudanças } \\
\text { consideradas importantes pelas } \\
\text { escolas e dialogadas com elas }\end{array}$ \\
\hline 8 & $14 \%$ & $\begin{array}{l}\text { Autonomia no planejamento } \\
\text { financeiro da área e execu- } \\
\text { ção financeira dos recursos }\end{array}$ & $\begin{array}{l}\text { Alta capacidade político-relacional interna, } \\
\text { média capacidade técnico-administrativa } \\
\text { (equipe conhece a política) e baixa capacida- } \\
\text { de político-relacional externa }\end{array}$ & $\begin{array}{l}\text { Objetivos estratégicos claros, foco } \\
\text { em avaliações e resultados edu- } \\
\text { cacionais, formação e acompa- } \\
\text { nhamento pedagógico baseados } \\
\text { em práticas de ensino }\end{array}$ \\
\hline
\end{tabular}


Como destacado anteriormente, a maioria das secretarias possuem autonomia de implementação, mas não no processo decisório, isto é, autonomia em relação à alocação de recursos garantidos pela legislação às políticas de educação. A discrição na alocação de recursos é condição necessária para permitir que os gestores tomem decisões sobre questões relacionadas ao cotidiano da pasta, que vão desde a contratação e gestão de pessoal às ações operacionais das políticas públicas.

A autonomia formal foi observada apenas nos casos 6 e 7, sendo o município 6 o que apresentou maior aumento comparativo no Ideb. Nos demais, prevalece a situação descrita pela técnica em contabilidade da secretaria do município 5: "a administração municipal diz que temos autonomia, mas não temos, (...) a palavra final não é nossa. Eles (Secretaria de Fazenda) não chamam a gente para fazer o orçamento de educação na LOA (Lei Orçamentária Anual)." O que também foi apontado pela própria secretária do município 3, que afirmou: "não há autonomia administrativa e financeira da pasta". A falta de autonomia financeira é agravada pelo desconhecimento dos profissionais de outras áreas sobre as peculiaridades da educação. Sobre isso, o servidor da secretaria do município 5 disse: "eles (Secretaria de Fazenda) não têm conhecimento técnico para debater o orçamento de educação. Quando começam a entender acaba o mandato (...)".

$\mathrm{Na}$ maioria dos casos, a autonomia também é prejudicada por processos internos e grau de formalização baixos, assim como por uma falta de clareza na divisão de res- ponsabilidades. Além disso, há uma ausência de carreiras específicas nas secretarias, sendo a maioria delas ocupada por diretores e professores das escolas, os quais, além de não necessariamente terem o conhecimento gerencial necessário, geralmente mudam de posição a cada troca de governo. Como colocaram vários entrevistados, todo o arsenal de práticas administrativas advém de mecanismos informais, que estão nas pessoas, e não na organização. $O$ resultado disso é, na maior parte das vezes, descontinuidade administrativa entre os governos.

A comparação entre os municípios mostra que a capacidade técnico-administrativa e político-relacional são fundamentais para que as secretarias possam aumentar a continuidade das políticas, estabelecer objetivos estratégicos, articular os diferentes programas e mobilizar as escolas em torno de metas, especialmente por meio do acompanhamento pedagógico. É importante apontar que apenas nos municípios 6 e 8 a secretaria atuou de forma dialogada e consensuada, demonstrando capacidade político-relacional, portanto, com atores escolares, 0 que, no caso do município 6 , foi fundamental para mobilizar gestores e professores em prol da implementação da política.

Sobre o acompanhamento pedagógico, se a rede não consegue apoiar efetivamente as escolas, o trabalho de melhoria da qualidade educacional nos municípios brasileiros tende a não ser bem-sucedido. Há casos em que se observa uma tentativa de relação mais próxima entre secretaria e escolas. Em um deles, por exemplo, além das visitas às escolas, a assessoras da secretaria reúnem-se bimestralmente com as coorde- 
nadoras pedagógicas para acompanhar a implementação da política. Em outros dois, há reuniões com a coordenação quinzenalmente e com os diretores a cada 20 dias.

Em outros casos, contudo, os entrevistados apontaram que fazem visitas, mas que a maior parte do contato ocorre por meio de ligações e de grupos no WhatsApp. Isso porque, em muitas das secretarias visitadas, 0 número de servidores responsável por esse acompanhamento não é suficiente para que eles realizem visitas periódicas às escolas. Além da baixa disponibilidade de burocratas, registra-se, igualmente, a escassez de recursos materiais das secretarias; em alguns casos, por exemplo, não há veículos disponíveis para ir às escolas. Como resultado dessa falta de padrão e de precariedade no contato com a secretaria, há relatos como de um dos diretores: "sentimos falta de respaldo do departamento, não vejo efetividade na supervisão que eles dão para a gente, a escola navega sozinha. [O departamento] só deu algumas diretrizes no começo do ano, mas não é possível ver nenhuma ação contínua e sistemática por parte dele." Ainda, continuou o entrevistado, "não existe uma diretriz municipal para a educação. Cada escola usa as diretrizes de um jeito, como for mais conveniente".

A capacidade político-relacional concentra-se nas formas de relacionamento entre secretarias e escolas, onde ela tem um papel primordial. No entanto, a fragilidade do controle social e a pouca importância da parceria com outros atores não-estatais revelam que outro elemento dessa capacidade politico-relacional, a de mobilização da sociedade em torno da relevância do setor, não foi significativa nos casos estudados.

\section{CONCLUSÃO}

Este estudo mostra, em primeiro lugar, que, apesar das limitações do conceito de capacidade estatal, ele pode contribuir para um debate comparativo sobre a relação entre burocracia e políticas públicas. Este estudo também aponta que o fortalecimento das capacidades de gestão das Secretarias é uma variável-chave para melhorar a qualidade educacional. A hipótese que pode ser levantada pelo presente estudo, mas que deve ser testada por novas pesquisas, é o quanto tais governos locais poderiam incrementar seus resultados educacionais caso tivessem maiores capacidades estatais.

A dimensão técnico-administrativa da capacidade estatal é ainda frágil na política educacional dos municípios analisados. Quando se imagina a Educação como uma política de Estado, e não de governo, essa fragilidade em termos de continuidade técnica é uma barreira para a melhoria de longo prazo dos resultados educacionais brasileiros. Soma-se a isso o fato de que a autonomia dessas Secretarias é fortemente afetada pela sua fragilidade em termos financeiros. Como a pesquisa mostrou, na maioria dos casos não é a educação que é a verdadeira dona do seu orçamento.

Nos casos em que a secretaria possuía autonomia, o perfil dos gestores foi central, na medida em que eram indivíduos com trajetórias profissionais anteriores no setor e, compreendendo a importância dessa autonomia, negociaram-na no início de suas gestões. A trajetória do gestor e de sua equipe na Educação faz com que eles tenham um repertório que parece equilibrar a falta de capacidade técnico-administrativa. 
A dificuldade em termos de capacidade estatal aparece também no seu aspecto político-relacional. A mobilização de atores externos à secretaria é quase incipiente, dificultando a projeção estratégica dessa política. A relação entre secretarias e escolas é o nexo mais importante da política educacional e aprimorar esse relacionamento é o principal instrumento para melhorar os resultados educacionais do país, especialmente em razão de as escolas serem muito frágeis do ponto de vista institucional como mostram indicadores financeiros, de gestão, de estabilidade do corpo funcional (principalmente pela saída constante dos professores) e da relação com as famílias.

Este estudo mostra, assim, que a União e os governos estaduais têm um papel enorme na criação de condições mínimas de gestão para que os municípios realizem as políticas educacionais. No entanto, paradoxalmente, para obterem da melhor maneira possível seu apoio, especialmente do plano federal, os municípios precisam de capacidades técnica, como já mostraram outros estudos (Grin, 2016). Ademais, a assistência da União, por ter de dar conta do conjunto das 5.570 municipalidades brasileiras, tende a ser mais genérica e de difícil customização para os problemas de cada município. A solução para isso seria incrementar o regime de colaboração entre os governos estaduais e municipais, o que reduziria muito os problemas informacionais e de controle do apoio oferecido. Porém, esse processo ainda é incipiente no país e o apoio federal continua a ser a peça-chave das administrações municipais na área educacional.

\section{Referências}

Aberbach, J., Putnam, R., \& Rockman, B. (1981). Bureaucrats and politicians in Western Democracies. Harvard University Press: Cambridge.

Arretche, M., Cordeiro, B. de S., Fusaro, E., Dias, E. C., \& Bittar, M. (2012). Capacidades administrativas dos municípios brasileiros para a política habitacional. São Paulo/Brasília: CEM/CEBRAP, Secretaria Nacional de Habitação/Ministério das Cidades.

Ayers, L., Kavanaugh, K., \& Knafl, K. A. (2003). Within-case and across-case approaches to qualitative data analysis. Qualitative Health Research, 13(6), 871-883. doi:10.1177/1049732303013006008

Bichir, R., Junior, S. S., \& Pereira, G. (2020). Sistemas Nacionais de Políticas Públicas e seus efeitos na implementação: O caso do Sistema único de Assistência Social (Suas). Revista Brasileira de Ciências Sociais, 35(102)1-23. doi: 10.1590/3510207/2020

Cardoso, F. H. (1975). Autoritarismo e democratização. Rio de Janeiro: Paz e Terra.

Carpenter, D. P. (2001). The forging of bureaucratic autonomy: Reputations, networks, and policy innovation in executive agencies, 1862-1928. New Jersey: Princeton University Press.

Cingolani, L. (2013). The state of state capacity: Areview of concepts, evidence and measures. Maastrich: Maastricht University - UNU-Merit. [Working Paper Series on Institutions and Economic Growth, 13]. 
Edigheji, O. (2010). Constructing a democratic developmental state in South Africa: Potentials and challenges. In O. E Edigheji. (org.). Constructing a democratic developmental state in South Africa: Potentials and challenges. Cape Town: Human Sciences Research Council.

Evans, P. (1995). Embedded Autonomy. Princeton: Princeton University Press.

Evans, P. (2010). Constructing the 21st Century Developmental State: Potentialities and Pitfalls. In O. E Edigheji. (org.). Constructing a democratic developmental state in South Africa: Potentials and challenges. Cape Town: Human Sciences Research Council.

Evans, P. (2011). The Capability Enhancing Developmental State: Concepts and National Trajectories. Center for Studies on Inequality and Development. Recuperado de $<$ www.proac.uff.br/cede>. (Discussion Paper, n. 63).

Fukuyama, F. (2013). What Is Governance? Governance, 26(3)347-368. doi: 10.2139/ ssrn.2226592

Gomide, A., Pereira, A. K., \& Machado, R. (2018). Burocracia e capacidade estatal na pesquisa brasileira. In R. Pires, G. S. Lotta, \& V. E. de Oliveira (eds.), Burocracia e políticas públicas no Brasil: Interseções analíticas (pp. 85-104). Brasília: IPEA.

Grin, E. (2016). Rotas federativas para a promoção de capacidades estatais municipais: Uma análise da experiência brasileira. Tese de Doutorado Fundação Getulio Vargas, São Paulo, São Paulo.
Grin, E., \& Abrucio, F. L. (2019). Las capacidades estatales de los municipios brasileños en un contexto de descentralización de políticas. Revista del CLAD Reforma y Democracia, 70, 93-126.

Harris, J. (2017). Achieving access: Professional movements and the politics of health universalism. Ithaca: Cornell University Press.

Koga, N., Viana, R., Camões, M., \& Filgueiras, F. (2019). Capacidades do serviço civil na implementação de políticas públicas: Resultados de um survey na Administração Federal Brasileira. In G. Lotta. (org.). Teorias e Análises sobre Implementação de Políticas Públicas no Brasil. Brasília: Enap.

Lavalle, A. G., Rodrigues, M., \& Guicheney, H. (2019). Agência local e indução federal: A operação da política municipal de habitação em Recife e Curitiba. Revista de Sociologia e Política, 27(71), 1-27. doi: 10.1590/1678987319277103

Loureiro, M. R., Olivieri, C., \& Martes, A. C. B. (2010). Burocratas, partidos e grupos de interesse: $O$ debate sobre política e burocracia no Brasil. In M. R. Loureiro, F. L. Abrucio, \& R. S. Pacheco (Org.). Burocracia e política no Brasil: Desafios para o Estado Democrático no século XXI (pp. 73-108). Rio de Janeiro: Editora Fundação Getulio Vargas.

Marenco, A. (2017). Burocracias Profissionais Ampliam Capacidade Estatal para Implementar Políticas? Governos, Burocratas e Legislação em Municípios Brasileiros. Dados, 60(4)1025-1058. doi: 10.1590/001152582017141

Pereira, A. K., Machado, R. A., Cavalcante, P. 
L. C., Gomide, A. D. Á., Bersch, K., MagaIhães, A. G., ... Pires, R. R. C. (2019). Qualidade do governo e capacidades estatais: Resultados do survey sobre governança aplicado no Brasil: projeto de pesquisa governança. Brasília: Ipea.

Peters, B. G. (2015). Policy capacity in public administration, Policy and Society, 34(3-4) 219-228. doi: 10.1016/j.polsoc.2015.09.005

Pires, R., \& Gomide, A. (2016). Governança e Capacidades Estatais: Uma análise comparativa de programas federais. Revista de Sociologia Política, 24(58)121-143. doi: 10.1590/1678-987316245806

Segatto, C., \& Abrucio, F. (2018). Os múltiplos papéis dos governos estaduais na política educacional brasileira: Os casos do Ceará, Mato Grosso do Sul, São Paulo e Pará. Revista de Administração Pública, 52(6)11791193. doi: 10.1590/0034-761220170047

Selznick, P. (1978). Cooptação: Um mecanismo para a estabilidade organizacional In E. Campos (org.). Sociologia da Burocracia (pp.93-100 ). 4- ed. Rio de Janeiro: Zahar Editores.

Skocpol, T. (1985). Bringing the state back in: Strategies of analysis in current research. In P. B. Evans, D. Rueschemeyer, T. Skocpol (orgs.). Bringing the state back in (pp. 3-43). New York: Cambridge University Press.
Souza, C. (2016), Capacidade Burocrática no Brasil e na Argentina: Quando a Política Faz a Diferença. In A. Gomide, R. Boschi (orgs.). Capacidades Estatais em Países Emergentes: O Brasil em Perspectiva (pp. 51-103). Rio de Janeiro: Ipea.

Souza, C. \& Fontanelli, F. (2020). Capacidade estatal e burocrática: Sobre conceitos, dimensões e medidas. In J. Mello, V. M. Ribeiro, G. Lotta, A. V. Bonamino, \& C. P. de Carbalho (orgs.). Implementação de políticas e atuação de gestores públicos: Experiências recentes das políticas de redução de desigualdades (pp. 45-71). Brasília: Ipea.

Weber, M. (1993). Parlamento e Governo na Alemanha reordenada: Crítica política do funcionalismo e da natureza dos partidos. Petrópolis: Editora Vozes.

Williams, M. J. (2020). Beyond state capacity: bureaucratic performance, policy implementation and reform. Journal of Institutional Economics, 1-19. doi: 10.1017/ S1744137420000478

Wilson, W. (2005/1887). O Estudo da Administração. Revista do Serviço Público, 56(3) 349-366. doi: 10.21874/rsp.v56i3.236

Wu, X., Howlett, M., \& Ramesh, M. (Eds.). (2018). Policy capacity and governance: Assessing governmental competences and capabilities in theory and practice. Gewerbestrasse: Palgrave Macmillan. 